\title{
Study of Osteoporotic Fractures Frailty Index
}

National Cancer Institute

\section{Source}

National Cancer Institute. Study of Osteoporotic Fractures Frailty Index. NCI Thesaurus.

Code C153302.

A frailty index consisting of 3 components: weight loss, the subject's inability to rise from a chair 5 times without using their arms, and reduced energy level. 